\title{
Micromixing efficiency in static mixer
}

\author{
J. Z. Fang, D. J. Lee* \\ Department of Chemical Engineering, National Taiwan University, Taipei, Taiwan, 106, ROC
}

Received 21 December 1999; received in revised form 26 December 2000; accepted 6 February 2001

\begin{abstract}
This work quantitatively measured the micromixing efficiency in the Kenics static mixer at Reynolds number ranging from 66-1,020 on the basis of a unique parallel competing reaction scheme proposed by Villermaux et al. Employment of the Kenics static mixer initiated early transition to turbulent flow. Furthermore, the mixer could markedly enhance the micromixing efficiency in both the laminar and turbulent flow regimes when compared with that in an empty tube. The mixing times data estimated according to an incorporation model substantially decreased with increasing Reynolds number, and ultimately reached a low level of $10^{-3} \mathrm{~s}$ in the turbulent flow regime. The present static mixer could yield better micromixing efficiency than that in a continuous-flow stirred tank reactor (CSTR) at the same power consumption rate. (C) 2001 Elsevier Science Ltd. All rights reserved.
\end{abstract}

Keywords: Micromixing; Kenics mixer; Segregation index; Measurement; Mixing time

\section{Introduction}

Mixing can quantitatively or even qualitatively alter the complex system dynamics when the mixing time is comparable to the reaction characteristic time (Villermaux, 1991; Lee, Chang, \& Mou, 1997). Ottino (1994) thoroughly reviewed pertinent literature before 1994 . Lamberto, Muzzio, Swanson and Tonkovich (1996) and Fountain, Khakhar, and Ottino (1998) demonstrated that the fluid mechanics involved in mixing systems could be rather complex.

Static mixers have found wide applications in industries (Middleman, 1977; Junker et al., 1994). Paul and Muschelknautz (1982) compared the pressure drop and the degree of mixing for twelve different types of static mixers. The Kenics mixer consists of alternating left- and right-handed helices with an angle of twist of $180^{\circ}$. Arimond and Erwin (1985); Khakhar, Franjione, and Ottino (1987) and Muzzio et al. (Hobbs \& Muzzio, 1997a,b, 1998; Hobbs, Swanson, \& Muzzio, 1998) numerically elucidated the velocity field, pressure drop, and residence time distribution of the static mixers. Most related works

\footnotetext{
* Corresponding author. Tel.: +886-6-2362-5632; fax: +886-2-2362-3040.

E-mail address: djlee@ccms.ntu.edu.tw (D. J. Lee).
}

considered the aspect of macromixing, by elucidating the residence time distribution (RTD) of mixers (Nigam \& Vasudeva, 1980; Nauman, 1982, 1991; Nauman \& Vasudeva, 1985; Kemblowski \& Pustelnik, 1988). However, as Khakhar, Franjione, and Ottino (1987) addressed, RTD cannot properly reflect the complicated flow characteristics in the static mixers. The information regarding micromixing efficiency in a static mixer is still large lacking in the literature.

Fournier, Falk, and Villermaux (1996a) reviewed pertinent literature on available measurement methods to micromixing efficiency. That work cited three main schemes for chemical methods: single reaction $(\mathrm{A}+\mathrm{B} \rightarrow \mathrm{R})$, consecutive competing reactions $(\mathrm{A}+\mathrm{B} \rightarrow \mathrm{R} ; \mathrm{R}+\mathrm{B} \rightarrow \mathrm{S})$, and parallel competing reactions $(\mathrm{A}+\mathrm{B} \rightarrow \mathrm{R} ; \mathrm{C}+\mathrm{B} \rightarrow$ $\mathrm{S})$; the latter two schemes can estimate the mixing efficiency by measuring the final product distribution (Treleaven \& Tobgy, 1973; Miyawaki et al., 1975; Phelan \& Stedman, 1981; Paul, Mahadevan, Foster, Kennedy, \& Milder, 1992). In related works, Bourne and co-workers proposed several schemes on the basis of consecutive competing schemes (Bourne \& Kozicki, 1977; Bourne, Crivelli, \& Rys, 1977; Bourne, Kozicki, \& Rys, 1981; Bourne \& Rohani, 1983).

Villermaux and co-workers (Villermaux, Falk, Fournier, \& Detrez, 1992; Villermaux, Falk, \& Fournier, 


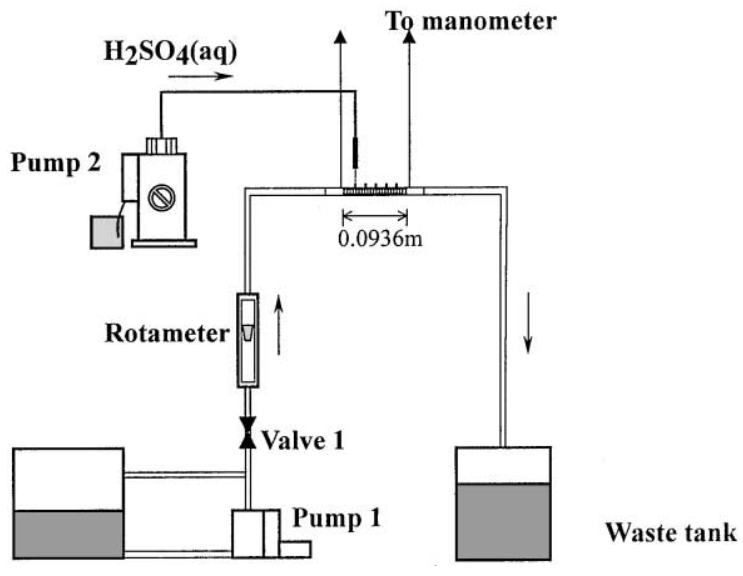

Fig. 1. The schematic of the experimental setup.

1994; Guichardon, Falk, Fournier, \& Villermaux, 1995, 1997; Fournier, Falk, \& Villermaux, 1996a,b) proposed a unique parallel competing reaction system with $\mathrm{A}, \mathrm{B}$, $\mathrm{R}$ and $\mathrm{S}$ as $\mathrm{H}_{2} \mathrm{BO}_{3}^{-}, \mathrm{H}^{+}, \mathrm{H}_{3} \mathrm{BO}_{3}$ and $\mathrm{I}_{2}$, respectively. Where $C$ denotes the mixture of $5 \mathrm{I}^{-}+\mathrm{IO}_{3}^{-}$. That is,

$\mathrm{H}_{2} \mathrm{BO}_{3}^{-}+\mathrm{H}^{+} \leftrightarrow \mathrm{H}_{3} \mathrm{BO}_{3} \quad$ (Quasi-instantaneously)

$5 \mathrm{I}^{-}+\mathrm{IO}_{3}^{-}+6 \mathrm{H}^{+} \leftrightarrow 3 \mathrm{I}_{2}+3 \mathrm{H}_{2} \mathrm{O} \quad$ (Fast).

Those investigators demonstrated that such a scheme is simple enough to permit easy analysis (spectrophotometrically) and has good sensitivity and reproducibility. On the basis of Villermaux's scheme, Lin and Lee (1997) measured the micromixing efficiency in an aerated stirred tank; Liu and Lee (1999) estimated the micromixing efficiency in a Couette flow reactor; while Liu, Lin, and Lee (1999) and Fang and Lee (2001) elucidated the spatial heterogeneity of micromixing environment in a continuous-flow-stirred-tank reactor (CSTR).

The Kenics static mixer, introduced in the mid-1960s, is a typical type of static mixer. In this work, we quantitatively estimate the micromixing efficiency in a Kenics static mixer, with the assistance of the unique parallel competing reaction scheme proposed by Villermaux et al. The corresponding mixing times are evaluated on the basis of the incorporation model proposed by Fournier et al. (1996b).

\section{Experimental}

A 12-element Kenics mixer of diameter $0.8 \mathrm{~cm}$ and of length per element $0.78 \mathrm{~cm}$ was chosen in this study $(L / D=1.03)$. Fig. 1 schematically illustrates the setup. The total length of the mixer is $9.36 \mathrm{~cm}$. The entrance length of the tube is $4.2 \mathrm{~cm}$, while the exit length is of $4.2 \mathrm{~cm}$ as well.

All chemicals were purchased from Merck Co., Taiwan at their highest purity, and were used without further purification. The boric acid and sodium hydroxide were initially added into deionized water to produce a solution at $\mathrm{pH} 10$. The concentrated solutions of potassium iodate and potassium iodide were then fed into the mixing section. The flow rate of solution ranged from 0.42 to $6.67 \mathrm{~cm}^{3} \mathrm{~s}^{-1}$, whose initial boric acid concentration was $0.0121 \mathrm{M}$; while for iodate, $0.00233 \mathrm{M}$; and for iodide, $0.0116 \mathrm{M}$. The corresponding Reynolds number based on empty tube ranged 66-1,060. The pressure drop was measured across the static mixer using a manometer.

Micromixing tests were proceeded with by slowly and continuously injecting sulfuric acid at a flow rate of $1.50 \mathrm{~cm}^{3} \mathrm{~min}^{-1}$ into the mixing section at either one of the five feed positions along the mixer. (Note: Preliminary tests demonstrated that if only the flow rate of acid were less than $2.0 \mathrm{~cm}^{3} \mathrm{~min}^{-1}$ the experimental results would not be affected by this flow rate, or the test was conducted under micromixing controlled regime.) Positions Nos. 1-4 were allocated at an interval of $2 \mathrm{~cm}$ along the mixer, while that for position No. $0,4.2 \mathrm{~cm}$ prior to the mixer (the entrance regime). The solution at the exit was collected and homogenized. Mass balance calculation revealed a negligible iodine loss.

If the local micromixing efficiencies were very efficient, most of the injected $\mathrm{H}^{+}$ions would be dissipated through Eq. (1). No iodine would form accordingly. If, on the other hand, the local mixing were insufficient, then, most of the injected $\mathrm{H}^{+}$ions would be dissipated stoichiometrically by Eqs. (1) and (2). The iodine forms accordingly, most of which would subsequently transform into tri-iodide ions according to $\mathrm{I}_{2}+\mathrm{I}^{-} \leftrightarrow \mathrm{I}_{3}^{-}$, whose $K=736 \mathrm{l} / \mathrm{mol}$. Based on the concentrations of the tri-iodide ions formed, the segregation index, $X_{s}$, could be estimated (Fournier et al., 1996a). By definition, $X_{s}=1.0$ for complete segregation, and $=0$ for perfect mixing. Independent tests reveal that the segregation index in a still liquid is approximately 0.98 , which partially confirms the validity of the current measurement. (Note: The details for the tests conducted in still liquid are available in Lin and Lee (1997).)

We herein estimated the concentration of tri-iodide ion at a wavelength of $353 \mathrm{~nm}$. To fit into the measurement range of the UV-visible spectrophotomer, the sulfuric acid concentration was set at $0.020 \mathrm{M}$ when feeding at position No. 0 . At positions Nos. $1-4$, on the other hand, the corresponding sulfuric acid concentration was $0.068 \mathrm{M}$ except for the case at position No. 1 and $R e_{\mathrm{EM}}=66$, whose acid concentration is identical to that for No. 0 .

\section{Results and discussion}

\subsection{Pressure drop}

In literature the pressure drop data were frequently reported as the $Z$-factor, which was defined as the ratio 


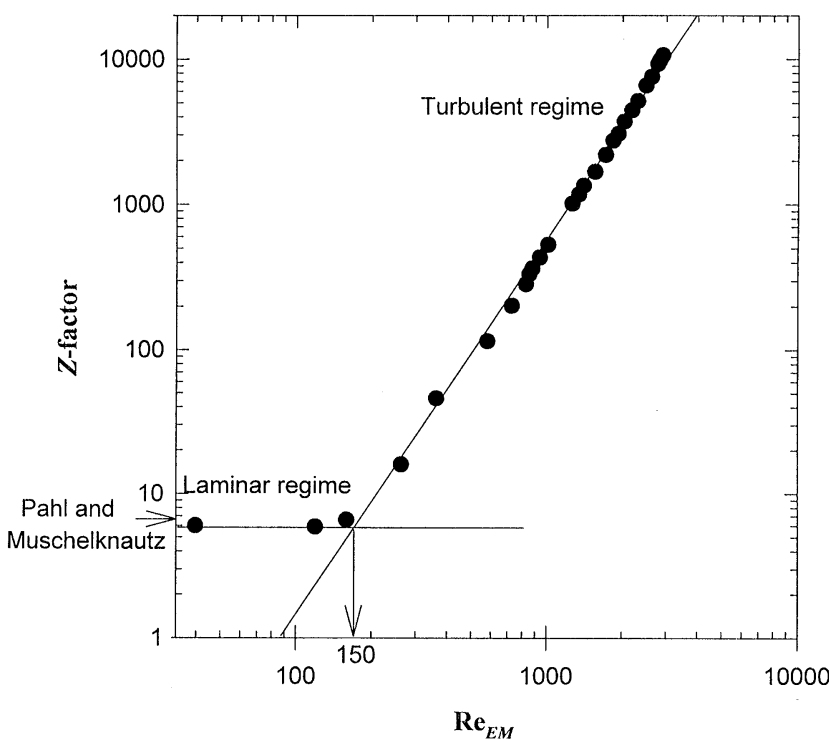

Fig. 2. $Z$-factor versus Reynolds number plot. Tube diameter $=0.8 \mathrm{~cm}$.

of $\Delta P_{\mathrm{SM}} / \Delta P_{\mathrm{EM}}$, where $\Delta P_{\mathrm{SM}}$ and $\Delta P_{\mathrm{EM}}$ are the pressure drops for static mixer and that for the empty tube, respectively (Boss \& Czaskiewicz, 1982). These values are based on the same $R e_{\mathrm{EM}}$, the Reynolds number for the empty tube, which is defined as $R e_{\mathrm{EM}}=D u / v$. Where $D, u$ and $v$ are the tube diameter, the mean flow velocity, and the kinematic viscosity, respectively. Fig. 2 depicts the $Z$-factor for the present mixer based on the pressure drop data measured herein. The laminar-turbulent transition could be located at approximately of $R e=150$, which correlates with Paul and Muschelknautz (1982). Such an observation suggests that the static mixer could initiate early transition to turbulence compared with the case of the empty tube $(2,100-4,000)$.

In pertinent literature some correlations for the $Z$-factor for the Kenics mixer are available, like Grace (1971); Chen (1973); Wilkinson and Cliff (1977); Paul and Muschelknautz (1982); and Heywood, Viney, and Stewart (1984), most of which are based on mixers of respect ratios exceeding unity. For the comparison's purpose, only the correlation of Paul and Muschelknautz (1982) for laminar flow is depicted as arrow in Fig. 2. The agreement is satisfactory.

\subsection{Segregation index}

During the Reynolds number range investigated herein $(66-1,060)$, the fluid flow at No. 0 should be in laminar flow regime. At a Reynolds number of 66, corresponding to low-Reynolds number, purely shear flow, the segregation index is approximately 0.7 , indicating a rather poor micromixed environment. Further increasing the Reynolds number reduces the segregation index substantially. For example, $X_{s}=0.25,0.17,0.13$, and 0.09 for $R e_{\mathrm{EM}}=159,265,477$, and 663, respectively. Notably, at the high-Reynolds number laminar flow in an empty tube could yield sufficient micromixing. For example, at $R e_{\mathrm{EM}}=1,060$, the segregation index becomes as low as 0.04 . Such an observation may be attributed to the interference of the feeding tip to the flowing fluid that generates local turbulence, which induces uncertainty in the $X_{s}$ measurement.

Next consider the static mixer case. At $R e_{\mathrm{EM}}=66$, the corresponding $X_{s}$ becomes lower than that for an empty tube: $X_{s}=0.48,0.47,0.52$ and 0.57 at position Nos. 1-4. The presence of static mixer could thereby markedly enhance the micromixing efficiency at the low-Reynolds number laminar flow regime. Notably, the $C_{\mathrm{H}^{+}}$at position 0 is different from that for position Nos. 1-4, the enhancement of micromixing by using static mixer cannot be directly compared. However, one could still note that (1) the static mixer has markedly improved the micromixed environment; (2) the micromixed environment for the first two elements is better than the subsequent elements of the mixer, as evidence by the lower $X_{s}$ 's for the former two elements.

At higher Reynolds number the $X_{S}$ decreases accordingly. For example, at position \#2, the $X_{s}=$ $0.17,0.08,0.05,0.04$ and 0.03 at $R e_{\mathrm{EM}}=159,265,477,663$ and 1,060, respectively. Restated, at a Reynolds number exceeding approximately 200 the segregation index can reach a low level less than 0.1 .

\subsection{Calculations of mixing time}

Segregation index cannot be directly used. Fournier et al. (1996b) employed an incorporation model for estimating the micromixing time, $t_{\mathrm{m}}$, which is an essential parameter for many micromixing models (Chang, Mou, \& Lee, 1996, 1999; Lee, Chang, \& Mou, 1997). Fournier et al. assumed a simple dilution-reaction scheme as stated in the following:

$\frac{\mathrm{d} C_{j}}{\mathrm{~d} t}=\left(C_{j 10}-C_{j}\right) \frac{1}{g} \frac{\mathrm{d} g}{\mathrm{~d} t}+R_{j}$,

where $C_{j}$ denotes the concentration of reactants, $C_{j 10}$ represents the surrounding liquid, $R_{j}$ is the reaction term, and $g$ denotes a function controlling the mass exchange rate between the fluid particle and the surrounding liquid. Eq. (3) comes from the realization that when a new fluid parcel enters the tank, its concentration, $C_{j}$, would change with time according to the mass exchange and dilution action of the surrounding liquid. A large $\mathrm{d} g / \mathrm{d} t$ denotes a fast dilution action, indicating a strong mixing effect between surrounding liquid and the injected liquid parcel. Fournier et al. (1996b) proposed two empirical forms: linear model and exponential model. More precisely, for the former, $g(t)=1+t / t_{\mathrm{m}}$; while for the latter, $g(t)=\exp \left(t / t_{\mathrm{m}}\right) . t_{\mathrm{m}}$ is the mixing time. Obviously, 


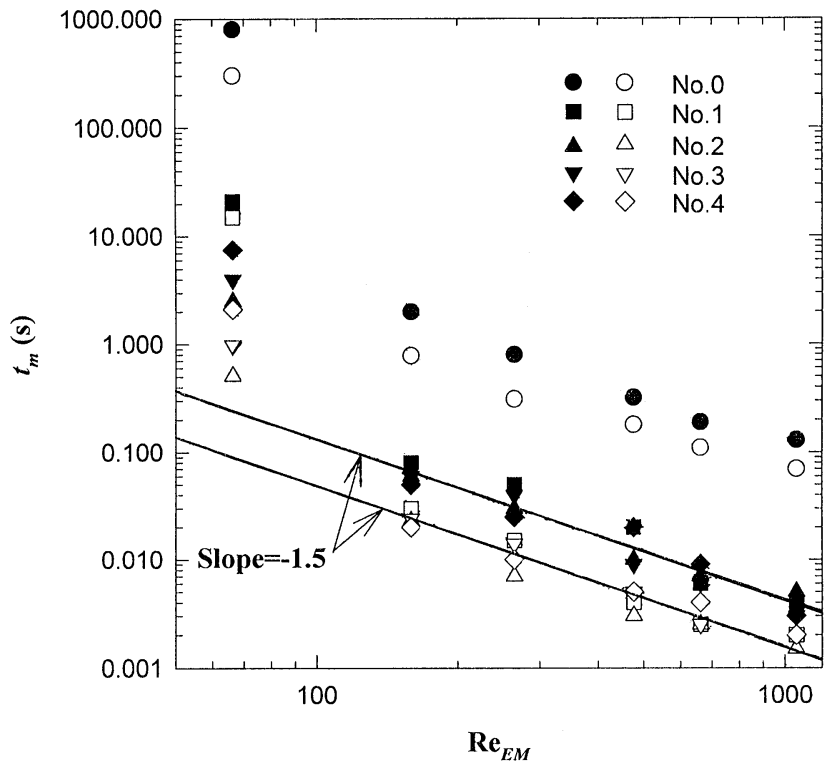

Fig. 3. Estimated $t_{\mathrm{m}}$ versus Reynolds number on the basis of fitting experimental data with the incorporation model. Closed symbols: exponential model, open symbols: linear model. The straight lines are the best-fitting lines with slope of -1.5 . Feed concentrations to determine $X_{s}$ : boric acid $=0.0121 \mathrm{M}$; iodate $=0.00233 \mathrm{M}$; iodide $=0.0116 \mathrm{M}$. Flow rate of sulfuric acid $(0.02 \mathrm{M})=1.50 \mathrm{~cm}^{3} / \mathrm{min}$.

for both models, a small $t_{\mathrm{m}}$ leads to a larger $\mathrm{d} g / \mathrm{d} t$, or equivalently, a better micromixing environment.

Fig. 3 summarizes the calculated mixing time data. At No. 0 , the $t_{\mathrm{m}}$ could reach $1000 \mathrm{~s}$ at $R e_{\mathrm{EM}}=66$. This unreasonable result is attributed to the inherent limitation of the incorporation model (Liu, Lin, \& Lee, 1999). We herein disregard this information. At greater $R e_{\mathrm{EM}}$ 's (663, say), $t_{\mathrm{m}}$ decreases to approximately $0.11 \mathrm{~s}$ (linear) or $0.19 \mathrm{~s}$ (exp). In the mixer section (Nos. 1-4), $t_{\mathrm{m}}-R e_{\mathrm{EM}}$ curves are similar to that for No. 0 , but at a lower value. Take No. 2 as an example, $t_{\mathrm{m}}$ is $2.5 \mathrm{~s}$ at $R e_{\mathrm{EM}}=66$. For $R e_{\mathrm{EM}}=663$, the corresponding $t_{\mathrm{m}}$ becomes $0.007-0.0025 \mathrm{~s}$. As is well known, when the mixing time is comparable to the characteristic time of chemical reaction, the mixing efficiency can markedly affect the yield and selectivity. The above $t_{\mathrm{m}}$ values can thereby serve as an initial estimate for designing a Kenics static mixer/reactor to fulfill a specific purpose.

Data for Nos. 1-4 in Fig. 3 reveal that the following power-law correlations exist for the obtained micromixing time at $R e_{\mathrm{EM}}>150$ :

$t_{\mathrm{m}}=a R e_{\mathrm{EM}}^{-n}$.

The exponent $n$ for all cases are all close to 1.5, while $a=2.12$ for exponential model and $=1.69$ for linear model. The average power consumption rate for the mixing section in the turbulent flow regime can be estimated as follows:

$\varepsilon_{V}=\frac{Q|\Delta P|}{V \rho}=\frac{Q|\Delta P|}{\frac{\pi}{4} D^{2} L \varepsilon \rho} \propto R e_{\mathrm{EM}}^{3}$,

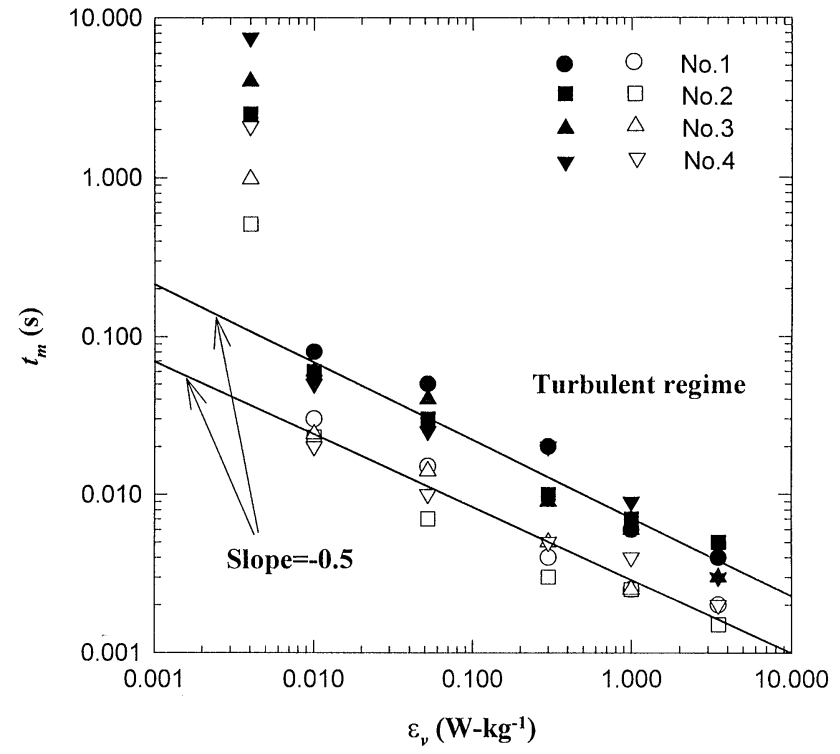

Fig. 4. $t_{\mathrm{m}}$ versus $\varepsilon_{v}$ plot. Closed symbols: exponential model, open symbols: linear model. The straight lines are the best-fitting lines with slope of -0.5 .

where $\varepsilon$ is the porosity of the mixing section. Consequently, in accord with Eqs. (4) and (5) the micromixing time is proportional to $\varepsilon_{v}^{-n / 3}$, or $\varepsilon_{v}^{-1 / 2}$. Fig. 4 depicts the $t_{\mathrm{m}}$ versus $\varepsilon_{v}$ curves. The $\varepsilon_{v}$ could reach $3.5 \mathrm{~W} \mathrm{~kg}^{-1}$, an order of magnitude similar to that found in a CSTR (Fournier et al., 1996b).

The best-fitting correlation for the present static mixer is as follows:

$t_{\mathrm{m}}=2.69 \sqrt{\frac{v}{\varepsilon_{v}}} \quad($ linear model $)$

and

$t_{\mathrm{m}}=7.08 \sqrt{\frac{\nu}{\varepsilon_{v}}} \quad($ exponential model $)$.

Such an observation reveals that, at the same power input rate, the Kenics mixer could yield a mode efficiently micromixed environment than in the continuous stirred tank reactor studied by Fournier et al. (1996b), whose correlation is $t_{\mathrm{m}}=17.24 \sqrt{v / \varepsilon_{v}}$.

\section{Conclusions}

This work quantitatively measures the micromixing efficiency in a Kinices static mixer on the basis of a unique parallel competing reaction scheme proposed by Villermaux and co-workers. The static mixer would initiate early transition to turbulence. The segregation index decreases with increasing Reynolds number, however, it revealed no sudden change at the hydrodynamic transition regime. The micromixing data were estimated based on the exponential and linear incorporation model proposed 
by Fournier et al. (1996b). The micromixing time decreases with increasing power consumption rate and ultimately reached a low level of $10-3 \mathrm{~s}$ in the turbulent flow regime. Comparisons with the micromixing efficiency in CSTR reveal that the present static mixer could yield a better micromixed environment than does the CSTR.

\section{Notation}

\begin{tabular}{|c|c|}
\hline$a$ & ing parameter, $\mathrm{s}$ \\
\hline$C_{j}$ & reactant's concentration, moll $^{-1}$ \\
\hline$C_{j 10}$ & 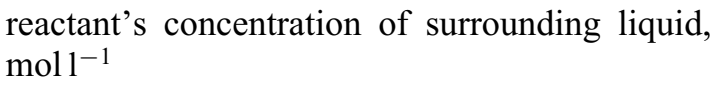 \\
\hline$D$ & diameter of the tube, $\mathrm{m}$ \\
\hline$g(t)$ & $\begin{array}{l}\text { function controlling mass exchange, dimension- } \\
\text { less }\end{array}$ \\
\hline$L$ & reactor length, $\mathrm{m}$ \\
\hline$n$ & exponent, dimensionless \\
\hline$\Delta P_{\mathrm{EM}}$ & pressure drop for empty tube, $\mathrm{Pa}$ \\
\hline$\Delta P_{\mathrm{SM}}$ & pressure drop for static mixer, $\mathrm{Pa}$ \\
\hline$Q$ & flow rate, $\mathrm{m}^{3}-\mathrm{s}^{-1}$ \\
\hline$R$ & reaction term, $\mathrm{moll}^{-1} \mathrm{~s}^{-1}$ \\
\hline$R e_{\mathrm{EM}}$ & Reynolds number for empty tube, dimensionless \\
\hline$t$ & time, $\mathrm{s}$ \\
\hline$t_{\mathrm{m}}$ & mixing time, $\mathrm{s}$ \\
\hline$V$ & void volume of the mixing section, $\mathrm{m}^{3}$ \\
\hline$u$ & mean fluid velocity, $\mathrm{ms}^{-1}$ \\
\hline$X_{S}$ & segregation index, dimensionless \\
\hline$Z$ & ratio of the pressure drops, dimensionless \\
\hline$\rho$ & liquid density, $\mathrm{kg} \mathrm{m}^{-3}$ \\
\hline$v$ & liquid kinematic viscosity, $\mathrm{m}^{2} \mathrm{~s}^{-1}$ \\
\hline$\varepsilon$ & porosity, dimensionless \\
\hline$\varepsilon_{P}$ & average power consumption rate, $\mathrm{W} \mathrm{kg}^{-}$ \\
\hline
\end{tabular}

\section{Acknowledgements}

National Science Council, ROC, had financially supported this work.

\section{References}

Arimond, J., \& Erwin, L. (1985). A simulation of motionless mixer. Chemical Engineering Commun., 37, 105-126.

Boss, J., \& Czaskiewicz, W. (1982). Principles of scale-up for laminar mixing processes of Newtonian fluids in static mixers. International Chemical Engineering, 22, 362-367.

Bourne, J. R., Crivelli, E., \& Rys, P. (1977). Chemical selectivity disguised by mass diffusion. Helvetica Chimica Acta, 60, 2944-2957.
Bourne, J. R., \& Kozicki, F. (1977). Mixing effects in the bromination of resorcin. Chemical Engineering Science, 32, 1538-1539.

Bourne, J. R., Kozicki, F., \& Rys, P. (1981). Mixing and fast chemical reaction. Chemical Engineering Science, 36, 1643-1648.

Bourne, J. R., \& Rohani, S. (1983). Micromixing and the selective iodination of 1-tyrosine. Chemical \& Engineering Research Design, 61, 297-302.

Chang, P. C., Mou, C. Y., \& Lee, D. J. (1996). Micromixing effects in a stirred tank: The random replacement IEM model. Chemical Engineering Science, 51, 2601-2606.

Chang, P. C., Mou, C. Y., \& Lee, D. J. (1999). Macromixing and micromixing effects on oscillations of apparent chemical reaction rates. Journal of Physical Chemistry A, 103, 5485-5489.

Chen, S. J. (1973). In-line, continuous mixing and processing of cosmetic products. Journal of Social Cosmetic Chemistry, 24, 639-653.

Fang, J. Z., \& Lee, D. J. (2001). Quantitative estimation of segregation indices in CSTR: effects of feed stream and output port. Journal of Chemical Engineering Japan, in press.

Fountain, G. O., Khakhar, D. V., \& Ottino, J. M. (1998). Visualization of 3-dimensional chaos. Science, 281, 683-686.

Fournier, M. C., Falk, L., \& Villermaux, J. (1996a). A new parallel competing reaction system for assessing micromixing efficiency-experimental approach. Chemical Engineering Science, 51, 5053-5064.

Fournier, M. C., Falk, L., \& Villermaux, J. (1996b). A new parallel competing reaction system for assessing micromixing efficiency-determination of micromixing time by a simple model. Chemical Engineering Science, 51, 5187-5192.

Grace, C. D. (1971). Static mixing and heat transfer. Chemical Processing \& Engineering, 52, 57-59.

Guichardon, P., Falk, L., Fournier, M. C., \& Villermaux, J. (1995). Study of micromixing on a liquid-solid suspension in a stirred reactor. A.I.Ch.E. Symposium Series, 305(91), 123-130.

Guichardon, P., Falk, L., Fournier, M. C., \& Villermaux, J. (1997). Extension of a chemical method for the study of micromixing process in viscous media. Chemical Engineering Science, 24, $4649-4658$.

Heywood, N. I., Viney, L. J., \& Stewart, I. W. (1984). Mixing efficiencies and energy requirement of various motionless mixer designs for laminar mixing applications. Institute of Chemical Engineers Symposium Series, 89, 147-176.

Hobbs, D. M., \& Muzzio, F. J. (1997a). The Kenics static mixer: a three-dimensional chaotic flow. Chemical Engineering Journal, 67, 153-166.

Hobbs, D. M., \& Muzzio, F. J. (1997b). Effects of injection location, flow ratio and geometry on Kenics mixer performance. A.I.Ch.E. Journal, 43, 3121-3132.

Hobbs, D. M., \& Muzzio, F. J. (1998). Optimization of a static mixer using dynamical systems techniques. Chemical Engineering Science, 53, 3199-3213.

Hobbs, D. M., Swanson, P. D., \& Muzzio, F. J. (1998). Numerical characterization of low Reynolds number flow in the Kenics static mixer. Chemical Engineering Science, 53, 1565-1584.

Junker, B. H., Seamans, T. C., Ramasubramanyan, K., Aunins, J., Paul, E., \& Buckland, B. C. (1994). Cultivation of attenuated hepatitis A virus antigen in a titanium static mixer reactor. Biotechnol. Bioengineering, 44, 1315-1324.

Kemblowski, Z., \& Pustelnik, P. (1988). Residence time distribution of a power-law fluid in Kenics static mixers. Chemical Engineering Science, 43, 473-478.

Khakhar, D. V., Franjione, J. G., \& Ottino, J. M. (1987). A case study of chaotic mixing in deterministic flows: The partitioned-pipe mixer. Chemical Engineering Science, 42, 2909-2926.

Lamberto, D. J., Muzzio, F. J., Swanson, P. D., \& Tonkovich, A. L. (1996). Using time-dependent rpm to enhance mixing in stirred vessel. Chemical Engineering Science, 51, 733-741. 
Lee, D. J., Chang, P. C., \& Mou, C. Y. (1997). Micromixing effects of autocatalytic reactions in a stirred tank: The random replacement IEM model. Journal of Physical Chemistry, 101, 1854-1858.

Lin, W. W., \& Lee, D. J. (1997). Micromixing effects in aerated stirred tank. Chemical Engineering Science, 52, 3837-3842.

Liu, C. I., \& Lee, D. J. (1999). Micromixing effects in a Couette flow reactor. Chemical Engineering Science, 54, 2883-2888.

Liu, C. I., Lin, W. W., \& Lee, D. J. (1999). Quantitative estimation of segregation indices in a CSTR on a unique parallel competing reaction scheme. Journal of Physical Chemistry A, 103, $1814-1817$.

Middleman, S. (1977). Fundamentals of polymer processing. New York: McGraw-Hill.

Nauman, E. B. (1982). Reactions and residence time distributions in motionless mixers. Canadian Journal of Chemical Engineering, 60, 136-140.

Nauman, E. B. (1991). On residence time and trajectory calculations in motionless mixers. The Chemical Engineering Journal, 47, 141-148.

Nauman, E. B., \& Vasudeva, K. (1985). Residence time distributions of power law fluids in motionless mixers. Canadian Journal of Chemical Engineering, 63, 519-521.

Nigam, K. D. P., \& Vasudeva, K. (1980). Residence time distributions in static mixers. Canadian Journal of Chemical Engineering, 58, $543-544$.
Ottino, J. M. (1994). Mixing and chemical reaction-a tutorial. Chemical Engineering Science, 49, 4005-4027.

Paul, E. L., Mahadevan, H., Foster, J., Kennedy, M., \& Milder, M. (1992). The effect of mixing on scaleup of a parallel reaction system. Chemical Engineering Science, 47, 2837-2840.

Paul, M. H., \& Muschelknautz, E. (1982). Static mixers and their applications. International Chemical Engineering, 22, 197-205.

Phelan, K. G., \& Stedman, G. (1981). Nitrogen tracer evidence for a cyclic azide species. Journal of Chemical Society Commun., 6 , 299-300.

Treleaven, C. R., \& Tobgy, A. H. (1973). Residence times, micromixing and conversion in an unpremixed feed reactor-II Chemical reaction measurements. Chemical Engineering Science, 28, 413-425.

Villermaux, J. (1991). Mixing effects on complex chemical reactions in a stirred reactor. Reviews of Chemical Engineering, 7, 51-108.

Villermaux, J., Falk, L., \& Fournier, M. C. (1994). Potential use of a new parallel reaction system to characterize micromixing in stirred reactors. A.I.Ch.E. Symposium Series, 299(90), 50-53.

Villermaux, J., Falk, L., Fournier, M. C., \& Detrez, C. (1992). Use of parallel competing reactions to characterize micromixing efficiency. A.I.Ch.E. Symposium Series, 286(88), 6-10.

Wilkinson, W. L., \& Cliff, M. J. (1977). An investigation into the performance of a static in-line mixer, Proceedings of the Second European Conference on Mixing, pp. 15-29. 